\title{
Erratum to: Quantification of land use/land cover changes in Pearl River Delta and its impact on regional climate in summer using numerical modeling
}

\author{
Wenshi Lin · Lu Zhang • Dongsheng Du • Limin Yang • \\ Hui Lin · Yuanzhi Zhang · Jiangnan Li
}

Published online: 9 January 2011

(c) Springer-Verlag 2011

\section{Erratum to: Reg Environ Change (2009) 9:75-82}

DOI 10.1007/s10113-008-0057-5

In the Original publication of this article, on page 81 , line 2 should read "13:00" instead of " $12: 00$ ", " $0.3^{\circ} \mathrm{C}$ " instead of " $0.16^{\circ} \mathrm{C}$ ", and the line following should read " $0.4^{\circ} \mathrm{C}$ " instead of " $0.2^{\circ} \mathrm{C} "$, " $1.8^{\circ} \mathrm{C}$ " instead of " $1.41^{\circ} \mathrm{C}$ ".

The authors regret that there is an error in Fig. 12 on page 81 . The correct figure is reproduced below:

The online version of the original article can be found under doi:10.1007/s10113-008-0057-5.

W. Lin $(\varangle) \cdot$ D. Du $\cdot$ J. Li

School of Environmental Sciences and Engineering,

Sun Yat-sen University, 510275 Guangzhou,

People's Republic of China

e-mail: eeslws@mail.sysu.edu.cn

L. Zhang $\cdot$ L. Yang $\cdot$ H. Lin · Y. Zhang

Institute of Space and Earth Information Science,

The Chinese University of Hong Kong,

Shatin, NT, Hong Kong

\section{Zhang}

State Key Laboratory for Information Engineering in Surveying, Mapping and Remote Sensing, Wuhan University,

430079 Wuhan, People's Republic of China 


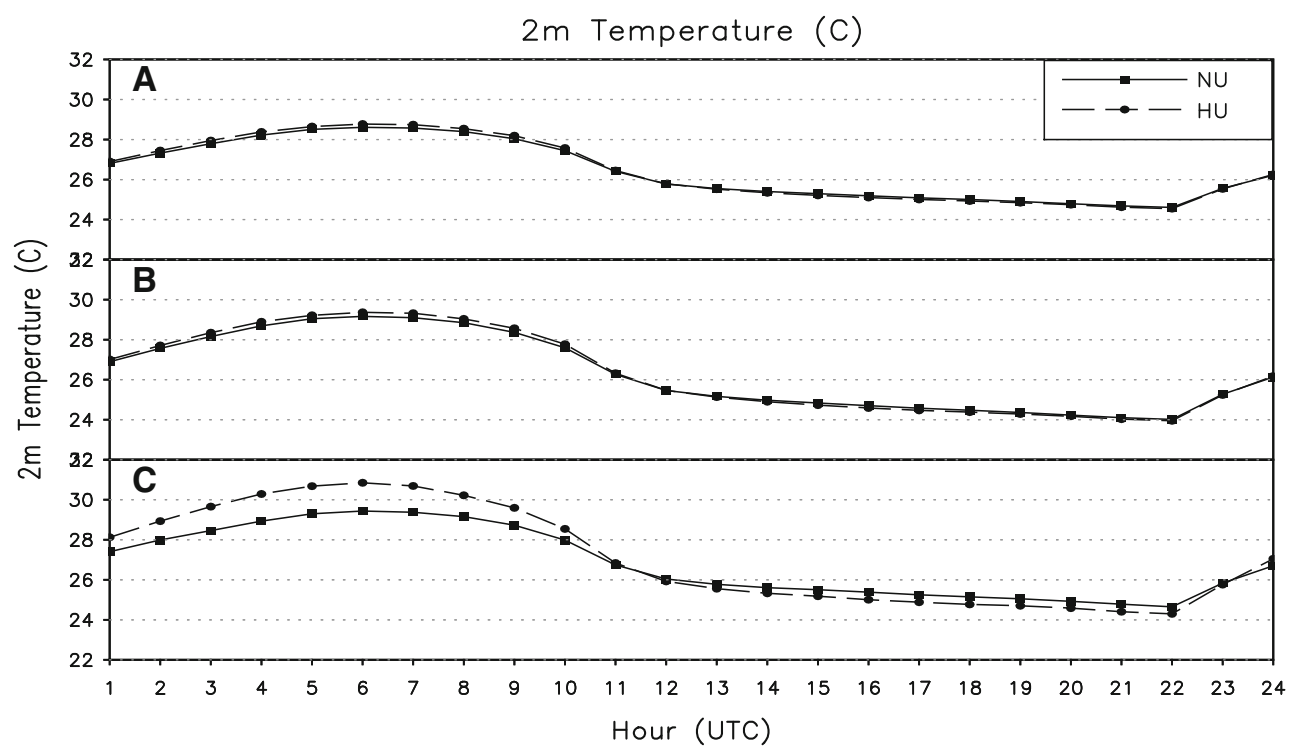

Fig. 12 Monthly average of the diurnal cycle of $2 \mathrm{~m}$ temperature from the model simulation for June 2005 (unit: ${ }^{\circ} \mathrm{C}$ ). a Averaged over all grid points in the domain D03 (domain-averaged). b Averaged over all land grid points in the domain D03 (land-averaged). c Averaged over all urban grid points in the domain D03 (urbanaveraged). Solid line is for NU and dash line for $\mathrm{HU}$ 